\title{
Crise da consciência contemporânea e expansão do saber não cumulativo*
}

\author{
Claudine Haroche* \\ Centre d'Études Transdisciplinaires: Sociologie, Anthropologie, Histoire - CNRS
}

Correspondência:

Claudine Haroche

22 rue d'Athènes

escalier B, 3ème étage

75009 Paris

e-mail: clharoche@aol.com

\section{Resumo}

Refletindo sobre os fins da universidade, este ensaio se questiona quanto à possibilidade mesma do ensino e, além disso, à possibilidade de conhecimento e de sentido nas sociedades contemporâneas, nas quais as condições de apropriação e de transmissão dos saberes estão profundamente transtornadas: uma incerteza às vezes radical quanto a si mesmo e quanto ao outro abre caminho para uma insegurança psíquica profunda. Os fluxos sensoriais contínuos provocam uma divisão inédita do trabalho dos sentidos, acentuando o papel da visão em detrimento dos demais; induzem a uma redistribuição das relações entre sensação, percepção, reflexão; e fortalecem a contingência, a instabilidade, a incerteza que se encontram no âmago da crise da cultura e da educação. 0 pensamento se encolhe, traduzido numa especialização, uma compartimentalização dos saberes. Que tipo de personalidade e de consciência, que forma de sensibilidade são estimuladas por essa educação? 0 que designa hoje em dia a palavra consciência? Poderemos ainda falar de atividade crítica? 0 pensamento individual, original, parece ter declinado diante da corporação, do grupo, do coletivo, legitimado pelo número, a quantidade, as exigências de produtividade e a avaliação por gestores, e tende, a partir daí, a se tornar cada vez mais homogêneo e conformista. Contudo, o ensaio busca mostrar que essas características, não sendo novas, foram apenas aceleradas e intensificadas na contemporaneidade, paradoxalmente, não nos privando de toda esperança quanto aos fins da universidade e às possibilidades do pensamento crítico.

\section{Palavras-chave}

Universidade - Contemporaneidade - Conhecimento - Consciência.

"Tradução de Lólio Lourenço de Oliveira e revisão técnica de Olgária Matos.

"Sou grata a Yves Déloye, Eugène Enriquez e Jacy Seixas por suas inúmeras observações, críticas e sugestões. 


\title{
The crisis of contemporary conscience and the expansion of non-cumulative knowledge*
}

\author{
Claudine Haroche* \\ Centre d'Études Transdisciplinaires: Sociologie, Anthropologie, Histoire - CNRS
}

\author{
Contact: \\ Claudine Haroche \\ 22 rue d'Athènes \\ escalier B, 3ème étage \\ 75009 Paris \\ e-mail: clharoche@aol.com

\footnotetext{
* Translated from the French by Lólio Lourenço de Oliveira; technical revision by Olgária Matos.

** I am thankful to Yves Déloye, Eugène Enriquez and Jacy Seixas for their many observations, critiques and suggestions.
}

\begin{abstract}
Reflecting on the purposes of university, this essay enquires as to the very possibility of teaching, and more than that, to the possibility of knowledge and meaning in contemporary societies, in which the conditions for the incorporation and transmission of knowledges are in disarray: an uncertainty, sometimes radical, about oneself and about the other paves the way to a profound psychic insecurity. The continual sensorial fluxes trigger a novel division of the work of the senses, highlighting the role of vision in detriment of the remaining senses, inducing a redistribution of the relations between sensation, perception and reflection, and strengthening the contingency, the instability, the uncertainty that are found at the heart of the culture and education crisis. The thinking shrinks, translated into a specialization, a compartmentalization of the knowledges. What kind of personality and of conscience, what form of sensibility is stimulated by such education? What does the word conscience mean these days? Can we still speak of critical activity? The individual, original thinking seems to have declined in the face of the corporation, of the group, of the collective legitimized by the number, the quantity, the demands for productivity and the evaluation by managers, and tends after that to become more and more homogeneous and conformist. Nevertheless, the essay seeks to show that these features, not being new, have just been accelerated and intensified by contemporaneity, and paradoxically do not deprive us of all hope as to the purposes of university and to the possibilities of critical thinking.
\end{abstract}

\section{Keywords}

University - Contemporaneity - Knowledge - Conscience. 
Toda obra científica acabada não tem outro sentido senão o de fazer com que surjam novas perguntas: assim, pois ela exige ser superada e envelhecer. (Weber, Le savant et le politique)

A autoridade baseava-se em uma fundação no passado que [...] dava ao mundo a permanência e o caráter duradouro de que necessitam os seres humanos precisamente por serem eles os mortais - os seres mais frágeis e mais fúteis que conhecemos. Sua perda equivale à perda dos alicerces do mundo que, de fato, a partir de então, começou a desarrumar-se, a modificar-se e a transformar-se numa velocidade cada vez maior, passando de uma forma a outra, como se vivêssemos e lutássemos com um universo proteu no qual o que quer que seja pode a qualquer momento transformar-se em praticamente o que quer que seja. (Arendt, La crise de la culture, Qu'est ce que l'autorité)

Numa fórmula de impressionante concisão, Benjamin (2000) deixou entrever as origens profundas da crise da consciência contemporânea. "Se a expressão ‘é de bom aviso' começa hoje a parecer obsoleta, isso se deve a que a experiência se torna cada vez menos comunicável” (p. 119), assim escreveu em 1936 em "le conteur".

Essa observação poderia explicar-se pela desatenção, pela indiferença que brota da igualização das condições na democracia ${ }^{1}$. Outrora, ao mostrar o caminho da sabedoria, o professor partilhava sua experiência, distribuía conselhos, indicava modelos a serem imitados, transmitia conhecimentos. Não conseguindo mais captar a atenção de seus alunos, já não seria mais ouvido nem compreendido: passou a dirigir-se a indivíduos rudes e desatentos.

Condensando uma vez mais sua proposição, Benjamin (2000) chega ao essencial: atribui essa incomunicabilidade ao fato de que "a arte da exposição tende a perder-se, porque o aspecto épico da verdade, ou seja, a sabedoria, está em vias de desaparecer" (p. 120) ${ }^{2}$.
A exposição foi pouco a pouco se tornando menos visível diante da informação que é instantânea e no mesmo instante ultrapassada, "a informação não tem valor a não ser no instante em que é nova. Ela só vive naquele instante" (Benjamin, 2000, p. 124). Elemento e efeito da intensificação da instantaneidade contemporânea, a informação teria efeitos profundos sobre a transmissão do saber, sobre sua existência mesma, contribuindo, de fato, para o desenvolvimento de um saber não cumulativo; poria em questão a possibilidade do ensino, mas além disso, a possibilidade de conhecimento e de sentido, sentido esse ao mesmo tempo partilhado e estruturante do eu. Permitindo, determinando, orientando o saber, decuplicando-o, desorientando-o e, ao mesmo tempo, obstruindo-o, a informação acabou por desempenhar um papel crucial relativamente aos fins da universidade ${ }^{3}$.

No início da década de 1950, Arendt (1972a) fará, em La crise de l'éducation, considerações profundamente ligadas àquelas do Benjamin, que dizem respeito à relação com o tempo, a duração, a tradição, a transmissão, em que é importante voltar, pelo tanto que nos parecem decisivas, para as questões sociais, morais, psicológicas e políticas das sociedades contemporâneas. Recordando então a oposição fundamental entre gregos e romanos e oposição entre um culto à aparência, à juventude, um abandono ao instante, por um lado e, por outro, um respeito pelo espírito, pela idade, uma busca de permanência, de eternidade, ela ilumina a situação contemporânea (Arendt, 1972a; 1972b; 1974) ${ }^{4}$. Ligado aos antigos, à autoridade moral que eles possuem, Arendt (1972a) acentua que

1. Tocqueville via na desatenção o vício maior da democracia (ver Haroche, 2001).

2. Ver Bobbio (2004).

3. As tecnologias da informação emanam e reforçam o igualitarismo, 0 nivelamento e a burocratização da sociedade. Sobre essas questões, ver McLuhan (1977); Ellul (1990); Illich (2004); Haroche (2005). Sobre essa intensificação e seus desenvolvimentos recentes, ver Aubert (2004).

4. Ver Haroche (2004a). 
a essência mesma do espírito romano [...] era considerar o passado enquanto passado como modelo e, em todo caso, os ancestrais como exemplos vivos para seus descendentes. Ele cria mesmo que toda grandeza reside naquilo que foi, que a velhice é pois o auge da vida de um homem e que, sendo já quase um ancestral, o idoso deve servir de modelo aos vivos. (p. 248)

Ela lembra que

os precedentes, as ações dos ancestrais e o costume que elas produziam estavam sempre ligados [...]. Também por isso é que a velhice, distinguida pelos romanos da pura e simples idade adulta, era vista como o momento em que se encontra o apogeu da vida humana: não tanto devido à sabedoria e experiência acumuladas, quanto devido à maior proximidade do idoso em relação aos ancestrais e ao passado. (p. 162-163)

Será que podemos, hoje em dia, ensinar e ao mesmo tempo aprender - e como, em sociedades caracterizadas pela fluidez - diante da existência desde então acelerada, intensificada de solicitações, de fluxos sensoriais, de formas de saber ilimitadas? (Gitlin, 2002; Turckle, 1995; llich, 2004). Que tipos de efeitos esses movimentos contínuos produzem sobre a consciência, sobre a capacidade de pensar e de refletir? (Haroche, 2004c; 2004d).

Os saberes constantemente mutáveis implicam e induzem ao transitório, ao efêmero, ao descontínuo, em suma, à instabilidade, um conhecimento que tende por razões intrínsecas à superficialidade, à pressa, um conhecimento difícil talvez mesmo impossível de aprofundar por falta de tempo.

As condições de apropriação e de transmissão dos saberes nas sociedades contemporâneas estão profundamente transtornadas: a crescente massa de informações contínuas nas sociedades contemporâneas, concomitante a uma reflexividade e a uma fluidez permanente, con- tribui para formas inéditas de individualismo, acarreta uma fragmentação, uma dispersão, um descomprometimento que obstrui de certo modo a continuidade, o sentimento de si mesmo (Bauman, 2000; Sennett, 1998; Kauffmann, 2003). Como desde então poucos conhecimentos são considerados adquiridos, definitivos, essas condições previnem a possibilidade de um saber cumulativo, provocam incerteza - uma incerteza às vezes radical - quanto a si mesmo e quanto ao outro, abrindo caminho para uma insegurança psíquica profunda.

A obra de Paul Hazard (1935) sobre $A$ crise da consciência européia e aquela que Husserl (1972) dedicou, uns quinze anos antes, A crise das ciências européias e a fenomenologia transcendental esclarecem ainda em profundidade a crise da consciência contemporânea, seus fundamentos, suas formas, sua especificidade.

Ao abordar questões a que se dedicou Arendt, Hazard (1935) recorda a busca de permanência, de estabilidade que valoriza ao máximo o fato de o século XVIl "evitar toda mudança [...] é a aspiração da idade clássica”, assim escreve ele, que cita Sêneca "o primeiro índice de um espírito bem regrado é poder deter-se, e permanecer consigo mesmo". Ele evoca então uma crise distante, aquela que "se operou na consciência européia entre o Renascimento, de que ela provém diretamente, e a Revolução Francesa, que ela prepara”. Essa crise tem a ver com a mudança, o movimento, o indivíduo: uma civilização fundada sobre a idéia de dever foi substituída por uma civilização fundada sobre a idéia de direito, os direitos da consciência individual, os direitos do cidadão (Hazard, 1935).

0 período contemporâneo em que o movimento se acentuou, decuplicou, intensificou, tornou-se contínuo, a partir de então, sem limites e sem fronteiras, volta a conhecer uma situação de crise na qual abandonaria radicalmente a idéia mesma de estabilidade (Gitlin, 2002) $)^{5}$.

5. Ver também Bergson (2003). 
Os efeitos psíquicos da mudança e do movimento contínuo é que seriam especialmente inéditos: de fato, até que ponto se pode pensar no movimento e, com isso, limitá-lo, retardálo, pelo menos alternar movimento e parada para poder pensar? 0 que se tornam os direitos da consciência individual e o indivíduo crítico diante de uma mudança permanente, da impossibilidade de deter-se, da injunção a prender-se a um eu, objeto de uma atenção contínua e sujeito de cuidado, de tormento incessante?

Devo ao texto de Hazard (1935) ter sido levado a compreender a necessidade de retornar ao Essai sur l'entendement humain: ao enunciar as condições do entendimento, Locke (2001) nos leva a interrogar sobre a possibilidade mesma de pensar nos excessos contínuos, que conduzem a meditar sobre o que podem a partir daí ser os fins da universidade.

Na Epístola ao leitor de seu Essai, Locke (2001) fez um relato concreto do intercâmbio havido num pequeno círculo que, pouco a pouco, conduziu à formulação das condições do entendimento.

Se não o aborrecesse conhecer o relato da história deste ensaio, eu lhe diria que cinco ou seis amigos reunidos em minha casa discutiam uma questão muito diferente desta; rapidamente viram-se detidos pelas dificuldades que surgiam de toda parte. Durante um momento, ficamos perplexos, sem chegar à solução das dúvidas que nos assaltavam; depois me veio ao espírito que havíamos começado de modo errado: antes de interrogar-se daquele modo, era necessário inicialmente examinar suas próprias capacidades e ver quais objetos podiam ser abordados pelo entendimento e quais não podiam sê-lo. Foi o que propus ao grupo que imediatamente concordou. (p. 38-39)

Quais são as capacidades exigidas para o exercício do pensamento? Como pensar e a partir de que objetos? Por si mesmo e com outros? 0 que é pensar? Não foram necessárias mais do que algumas linhas para que locke
(2001) formulasse as condições, as regras, as limitações, as exigências e os objetos do entendimento. Observando a formação das idéias, compreendendo os funcionamentos da consciência, Locke viu na percepção "a primeira etapa no caminho do conhecimento [...], entrada de todo conhecimento no espírito" (p. 242).

Num capítulo dedicado à percepção e às condições de seu exercício, locke (2001) assinalará o caráter ativo do pensamento, que supõe “certo nível de atenção voluntária”, o que o distingue da percepção que tende a ser passiva; "na pura e simples percepção, o espírito é em sua maior parte apenas passivo e o que ele percebe não pode deixar de perceber" (p. 233) ${ }^{6}$.

Locke (2001) empenha-se, a seguir, em apreender os processos que atuam na percepção, evocando a evidência experimentada por todos os indivíduos, o papel dos sentidos nos processos de conhecimento e de pensar; "cada qual o saberá ao refletir sobre o que ele próprio faz quando vê, ouve, sente [...] ou pensa, mais do que por meio de todo o discurso que eu possa fazer" (p. 234) ${ }^{7}$.

Observando as relações entre as sensações e as idéias, as percepções e os juízos, Locke (2001) entrevê os elos entre o hábito, a repetição e a rapidez e, nesta, a desatenção a que ela induz: observa, descreve e dá a conhecer, demonstra a passagem da percepção para a idéia pela repetição, pelo hábito; demonstra igualmente a confusão entre percepção da sensação e idéia formada pelo juízo.

Em inúmeros casos, uma vez instalado o hábito no que é objeto de experiência freqüente, isso se produz de modo tão constante e tão imediato que toma-se por percepção da sensação o que é uma idéia formada pelo juízo (p. 239).

Para além da repetição, do hábito, ele distingue o papel decisivo da rapidez que ex-

6. Ver Merleau-Ponty (2001).

7. Sobre a dificuldade de definir passividade e atividade, ver Weber (1971). 
plica o fato de nem sempre podermos distinguir claramente nem as percepções nem os julgamentos do espírito.

Atualmente, como outrora, tudo nasceria da sensação na qual locke vira o fato primitivo: a sensação hoje em dia, no entanto, não mais conduziria infalivelmente à idéia; a repetição freqüente do hábito leva a que se coloque em primeiro plano a sensação e em segundo as idéias e os juízos: o caráter contínuo da sensação tenderia a reduzir, diminuir, talvez mesmo a descartar o que cabe à idéia, ao pensamento, à reflexão (Haroche, 2004c).

locke leva-nos assim a meditar sobre a evolução das formas contemporâneas de percepção por razões profundas que têm a ver, entre outras, com a aceleração, a velocidade, a tecnologia. Os fluxos sensoriais contínuos provocam de fato uma divisão inédita do trabalho dos sentidos: acentuando o papel da visão em detrimento dos demais sentidos, induzem a uma redistribuição das relações entre sensação, percepção, reflexão, e fortalecem a contingência, a instabilidade, a incerteza que se encontram no âmago da crise da cultura e da educação (Haroche, 2004d).

Locke pôs em evidência a noção do indivíduo moderno, liberto contra a tradição, os direitos da consciência, o papel concomitante dos fatos e da psicologia.

Isso representa a supressão dessa concomitância entre fatos e consciência, o descartar da consciência, da subjetividade nos fatos, que os escritos de Husserl (1972) se dedicarão a revelar, permitindo assim entrever alguns dos elementos que devem conduzir a uma crise da consciência e da subjetividade contemporânea.

Husserl (1972) insiste sobre a perturbação que se produziu nas ciências no final do século XIX: isso levará ao positivismo da ciência que "em nossa época permitiu a queda de todas as questões [...] metafísicas em sentido amplo, ou seja, as questões especificamente filosóficas" (p. 13-14) ${ }^{8}$. Ele observa que a subjetividade foi posta de lado pelo positivismo "a idéia da ciência reduziu-se nele a uma sim- ples ciência dos fatos" -, assinalando que essa redução provocou uma crise da ciência que, entre outras coisas, tem a ver com "a perda de sua importância para a vida, para as mais importantes questões do sentido da existência” (p. 9). Husserl evoca brevemente o que Hazard assinalará, por sua vez, no início da década de 1960, o momento revolucionário em que a Europa do Renascimento, voltando-se contra os modos de existência da ldade Média, empenha-se em libertar-se da tradição em geral, buscando substituí-la por uma abordagem refletida e crítica do mundo.

Ele assinala que as ciências deixaram de ater-se a um certo número de questões mais importantes relativas à subjetividade, à consciência, ao compromisso, ao sentido, que "jamais foi verdadeiro que as questões especificamente humanas tenham sido banidas da esfera da ciência”: ele pergunta então por que razão a ciência "perdeu o papel condutor, por que chegamos a uma alteração essencial da idéia de ciência, com a limitação positivista", interrogando-se sobre as razões do êxito das ciências positivas que se alojaram "puramente na superfície” (Husserl, 2001, p. 11-12).

A redução positivista da ciência, a insistência exclusiva sobre o fato e a neutralidade e, portanto, o descomprometimento do sujeito para com o conhecimento tornado então objeto, caminhando par a par com o descarte do subjetivo, "as questões que ela exclui por princípio, são precisamente as questões que são as mais candentes [...] aquelas ... que dizem respeito ao sentido ou à ausência de sentido de toda essa existência humana", interrogações complexas que pressupõem a dúvida, reconhecem a incerteza, estão no cerne dos problemas da universidade contemporânea (Husserl, 2001, p. 10) ${ }^{9}$.

Em 1935, numa conferência no círculo cultural de Viena, Husserl irá novamente propor a questão da crise das ciências européias.

\footnotetext{
8. Do mesmo modo, Arendt (1996) observa, em suas Considérations morales, o desprezo de que a metafísica é objeto atualmente. 9. Ver Weber (1971).
} 
A crise da consciência, provocada ou, pelo menos, fortalecida pela relação com o tempo, a rapidez, hoje decuplicada pela aceleração, teria sua origem no fato de a ciência não ter mais tempo de aprofundar as questões para além dos fatos, de compará-los, de descobri-los, de discernir um sentido para eles: ela se traduziria por uma acumulação irrefletida dos fatos que implica uma ausência de aprofundamento, de problematização psicológica e antropológica, provocando efeitos psicológicos inéditos ${ }^{10}$.

Husserl (2001) leva-nos a meditar sobre as condições contemporâneas da reflexão e da consciência quando relata a emergência, o status e o modo de desenvolvimento das idéias e da ciência, fazendo desse modo distinção entre um saber cumulativo e um saber não cumulativo, as idéias "têm uma existência efêmera no mundo ambiente", constituem "formações de sentidos produzidas nas pessoas individuais e que são de um gênero novo e surpreendente, que consistem em guardar dentro de si infinidades intencionais, essas idéias [...] entram no movimento de uma reelaboração perpétua" (355-356) ${ }^{11}$. Ele as opõe às aquisições científicas cuja "produção foi conquistada, (que) possuem um modo de ser e uma temporalidade completamente diferentes. Elas não são superadas, não são passageiras” (p. 357).

Husserl leva-nos a concluir pelo caráter permanente e unificado do conhecimento científico que permite a construção e, de fato, o valor diante do caráter efêmero, contingente $\mathrm{e}$ variável das idéias, das formações dos sentidos cujo status é ali depreciado, desprezado e até estigmatizado.

Na década de 1930, Husserl (2001) chegará a compreender que a ciência, eterna, absoluta, é no entanto inacabada, e assim potencialmente mutável, e observará então que "a cultura científica dominada pelas idéias de infinidade significa pois uma revolução do conjunto da cultura, uma revolução no modo de ser da humanidade em seu conjunto enquanto criadora de cultura" (p. 358-359) ${ }^{12}$.

0 interesse de voltar ao texto de Husserl
(2001) é claro: ele permite elucidar a atitude para com as idéias e para além da cultura geral. 0 status das idéias, sua contingência, sua instabilidade, é crucial para compreender a prudência, a desconfiança, a desvalorização, o desprezo, a rejeição e até mesmo o ódio que hoje em dia podem suscitar nos espaços universitários não só determinadas idéias, mas a noção mesma de idéia e, nesta, fundamentalmente, a individualidade, a singularidade, a originalidade, o variável, o diferente, o diverso, o não redutível, o não controlado e controlável: o que pode escapar às normas, às exigências de normalização, seria rejeitado muitas vezes com uma violência, uma crueldade extrema, que revela formas de niilismo radical (Balibar, 1996) $)^{13}$ :

a exigência de submeter o conjunto do empírico a normas ideais, a saber as da verdade incondicional, essa exigência dá origem ao mesmo tempo a uma mutação, que vai bem mais longe, do conjunto da práxis da existência humana, em outras palavras de toda a vida cultural; esta não deve mais deixar-se normatizar pelo empírico cotidiano e pela tradição em sua ingenuidade, mas pela verdade objetiva. (Husserl, 2001, p. 367-368)

A experiência cotidiana e a tradição ingênua, os usos e os automatismos delas decorrentes, acompanhados de ausência de reflexão e, ao mesmo tempo, de uma reflexividade contínua, permitiriam entrever nas sociedades contemporâneas uma normatividade e uma con-

10. Do mesmo modo, Arendt (1996) observa em suas Considérations morales, o desprezo de que a metafísica é objeto atualmente.

11. Ver Weber (1971).

12. Essa acumulação irrefletida é concomitante a uma reflexividade contínua que convém seja distinta da reflexividade de que fala Castoriadis (1975), da reflexão que implica tempo, uma alternância entre momentos de pausa e de atividade no pensamento. Uma genealogia dessas questões que estão presentes nas origens da modernidade, da racionalidade do capitalismo, encontra-se em Castoriadis (1999) e também em Haroche (2004c; 2004d).

13. "Seria preciso que os sábios das ciências do espírito não tratem simplesmente do espírito enquanto espírito, mas que recuem até a infraestrutura corporal" (Husserl, 2001, p. 349). Sobre essas questões, ver Janet (1989) e Anzieu (1995). 
formidade despercebida que conservam o antigo e abrem para as idéias de infinidade.

"A forma espiritual da Europa", assinalava Husserl (2001) de forma extraordinariamente sintética,

é um novo espírito oriundo da filosofia e de suas ciências subordinadas, um espírito de livre crítica e de normalização por tarefas infinitas que, a partir de então, dominam de ponta a ponta a humanidade e criam ideais novos e infinitos. (p. 370)

Os fins da universidade revelariam, assim, exigências profundamente paradoxais, talvez até mesmo contraditórias.

Arendt (1972a) foi particularmente sensível a essa dimensão paradoxal em um texto da década de 1950, dedicado à crise da educação:

parece-me que o conservadorismo, tomado no sentido de conservação, constitui a essência mesma da educação, cuja tarefa é sempre a de cercar e de proteger alguma coisa, a criança contra o mundo, o mundo contra a criança, o novo contra o antigo, o antigo contra o novo. (p. 246) ${ }^{14}$

Prefigurando a questão da fragmentação, da descontinuidade, a ausência de transmissão entre gerações nas sociedades contemporâneas, Arendt (1972a), indo além dos escritos de Weber, observava a propósito da situação da década de 1950 que uma crise da educação é "o reflexo de uma crise muito mais geral [...] da instabilidade da sociedade moderna”. Ela colocava em evidência um aspecto paradoxal do mundo contemporâneo:

está claro que ao tentar instaurar um mundo próprio para as crianças, a educação moderna destrói as condições necessárias do desenvolvimento delas. (p. 238, 240) ${ }^{15}$

Diferentemente de Arendt, que discerne uma evolução contemporânea na crise da educação e mais amplamente da cultura, Voegelin
(2003) centrou sua atenção na universidade alemã: ele busca as raízes dessa crise na concepção mesma de Humboldt que não quis ver na universidade senão um lugar de formação apenas da consciência individual, indiferente ao espaço público. Apegando-se

ao culto da individualidade, essa formação revela então um voltar-se sobre si mesmo, uma estreiteza de espírito, um encolhimento dos interesses, que não é uma educação para a abertura do espírito; é uma ação de fechamento deste. (p. 330) ${ }^{16}$

Voegelin (2003) discerne assim, ao estudar esse tipo de universidade,

um espaço público de alienação que domina no plano social, explicando então a desagregação da sociedade pelo fato de que seus membros se concebem única e radicalmente como homens privados [...]. (p. 308) ${ }^{17}$

Ele assinala que essa universidade tem em si mesma uma função ideológica,

14. Arendt (1972a) distinguia o espírito grego do espírito romano, opondo o reinado do corpo, da aparência, da juventude, do instante entre os gregos, à experiência, ao fato de tornar-se, com a idade, um modelo que supõe a continuidade, a permanência, a eternidade. Ela mostrava que 0 espírito romano "está em contradição não só com nossa época e os tempos modernos do Renascimento, mas também, por exemplo, com a atitude grega perante a vida. [...] A concepção latina seria de que é justamente envelhecendo e desaparecendo pouco a pouco da comunidade dos mortais que 0 homem atinge sua mais característica maneira de ser mesmo se em relação com o mundo das aparências, está em vias de desaparecer; pois é somente então que ele alcança esse modo de existência em que será uma autoridade para os outros (p. 248).

15. Sobre as questões de continuidade, ver Haroche (2004b; 2004c).

16. Sou grata a Paul Zawadzki por haver chamado minha atenção para os escritos de Voegelin sobre essas questões. Ver também Dumont (1991). Weber havia tornado visível uma questão essencial na Reforma protestante, a emergência de uma racionalidade específica ao capitalismo ocidental: a especialização que é indissociável do individualismo crescente e das formas de subjetividades que se definem pelo trabalho.

17. Voegelin (2003) observa contudo que a universidade alemã "contradisse por mais de uma vez a concepção de Humboldt, particularmente durante 0 período que sucedeu à Primeira Guerra Mundial. A universidade de Heidelberg da década de 1920, onde se encontravam ao mesmo tempo homens como Jaspers, [...] Alfred Weber [...], era tudo menos uma universidade concebida à maneira de Humboldt" (p. 334). Sobre a alienação, ver Adorno (1989). 
a formação (Bildung) dispensada à universidade imuniza suas vítimas [...] contra a vida do espírito; ela é bem sucedida em manter a alienação numa posição de dominação social; e impede que o espaço do espírito se torne um espaço público social. (p. 332)

Voegelin (2003) observa, colocando fundamentalmente a questão do pensamento, do juízo, da consciência crítica, o funcionamento de uma tal universidade a propósito da história ${ }^{18}$. Desse modo, opõe a uma história crítica, em que apenas a interpretação e o juízo podem permitir o saber cumulativo, uma história descritiva, rica em detalhes, mas desprovida de reflexão, de análise crítica, uma história suscetível de levar a um saber algo descompromissado, superficial, descontínuo, não cumulativo: a acumulação ilimitada de fatos e pormenores não permite compreender os acontecimentos sociais e históricos, ela não equivale à consciência crítica, à atividade crítica. Voegelin toma então o exemplo das gerações jovens que, na Alemanha, buscam compreender o passado nazista, "vocês, os jovens, não querem saber os pormenores de como essas coisas atrozes se desenrolaram, mas sim por que se chegou àquilo, e como aquilo poderia ser evitado no futuro. Mas de que modo uma descrição histórica poderia interromper a continuidade em que vocês se inscrevem e tornar impossivel a repetição daqueles acontecimentos?" E ele conclui daí que "se o espírito como instância crítica é excluído da reflexão sobre os acontecimentos, então a objetividade da descrição transforma-se em uma simpatia culpada pelo estado de ausência de espírito" (p. 303, 305).

Voegelin (2003) observa a propósito dos trabalhos dedicados ao nazismo que o que inquieta não é seu tema, mas o conhecimento desapaixonado da realidade porque o prazer do conhecimento implica sempre uma certa aprovação. Ele examina a questão da universidade alemã durante o nazismo, indagando-se como

se pode reparar um erro pela reconstrução do passado, por mais meticulosa que seja. Em nosso caso concreto, a confiança na universidade alemã poderá restabelecer-se por uma descrição do comportamento dos professores e estudantes sob o 111 Reich? Sem dúvida, não, porque cada novo pormenor abala ainda mais essa confiança. (p. 305, 306)

Assim, Voegelin (2003) aborda um conjunto de questões cruciais hoje em dia para "os fins da universidade" e mais amplamente para as formas de individualismo e de narcisismo das sociedades contemporâneas, procurando precisar o lugar, o papel do narcisismo na cultura e fala então de uma teoria narcisista da cultura: a ausência de conhecimento, de espírito, de consciência crítica acarreta a conivência (mais do que a complacência), a simpatia, algo de intangível, da ordem do clima, da atmosfera tanto psicológica quanto política.

0 que falta, escreve ele, é a compreensão verdadeira, graças à qual o espírito, como potência crítica, torna-se um fator de ruptura da causalidade histórica, aparentemente impossivel de ser rompida. (p. 305)

$$
\text { Propõe, assim, que }
$$

a universidade alemã tem por missão encerrar as pessoas de um modo narcisista, de privá-las de qualquer orientação espiritual, de torná-las inaptas para a vida pública, de destruir a língua alemã e de ensinar os idiomas da alienação. (p. 337)

Indagando-se sobre a situação contemporânea, Voegelin observa uma mudança: o que é novo em relação ao período Weimar é o sentimento de culpa de que queremos nos livrar por meio de um reconhecimento objetivo e escrupuloso dos acontecimentos. Ora, precisamente com esse sentimento de culpa é que devemos ter cuidado, porque ele é contrário à

18. Gauchet (2002) observará de sua parte o funcionamento da universidade contemporânea a propósito da concepção e do ensino da filosofia. 
condenação fundada na alienação de nosso próprio ser”. Ele examina, então, as conseqüências disso e conclui daí que

o sentimento de culpa experimentado uma vez realizado o ato não é a mesma coisa que a simpatia experimentada antes que ele seja cometido. Mas essa simpatia e esse sentimento de culpa estão intimamente ligados como expressão de uma conivência devida a sua ausência de espírito. (p. 306-307) ${ }^{19}$

Marcel Gauchet, ao apegar-se à questão da educação, e Lindsay Waters, ao interessar-se pelas origens e pelos efeitos dos saberes especializados e experientes, debruçaram-se recentemente sobre essa crise da consciência contemporânea.

Gauchet (2002) observa a dificuldade, talvez mesmo a impossibilidade, da atividade de pensar nas condições contemporâneas de educação. Essa dificuldade se manifesta por um "encolhimento" do pensamento, traduzido numa especialização, uma compartimentalização dos saberes que, descartando as indagações gerais sobre os fundamentos, leva a um pensamento repetitivo e prudente. Ele percebe esse encolhimento de maneira particularmente clara na filosofia e no seu ensino. Vê a origem disso

do exercício injustificável de uma proscrição, da recusa em admitir a legitimidade de uma filosofia compreendida de modo diferente de uma história da filosofia, e uma história da filosofia definida de maneira a mais acanhada. (p. 12)

Gauchet (2002) dedicou-se de certo modo a esclarecer uma explicação da idéia de conservação e sugere então "uma tentativa que vise à explicitação dos fundamentos e dos fins". "Por que educar? Com vistas a quê?”, ele se indaga. A conservação se reduziria ao conservadorismo que, sob a capa de exigência de modernização do saber, de adaptação a novas realidades sociais, entrava o saber cumulativo, induz a um saber não cumulativo, estreitamente especializado, rapidamente superado e ultrapassado. Produz-se no pensamento uma perda da inteligibilidade, uma perda de sentido, uma especialização sem fim nem razão, uma ilegibilidade. "Ao desenvolver-se, os saberes perderam de vista sua razão de ser” (p. 14) ${ }^{20}$.

0 indivíduo contemporâneo quer ser informado, especializado e experiente para um mercado que o amedronta, e não educado, instruído; já não busca um conhecimento desinteressado a longo prazo, um conhecimento que não esteja imediatamente ligado ao imediatismo do mercado, mas que vise a valores universais e compartilhados. "Não que ele recuse a educação. Ao contrário, ele aspira a ser formado", mas, acrescenta Gauchet (2003), “ele não é por isso menos tendencialmente ineducável [...] uma coisa é exigir educação, outra coisa é ser capaz de recebê-la" (p. 332).

Que tipo de personalidade e de consciência, que forma de sensibilidade é estimulada por essa educação? 0 que designa hoje em dia a palavra consciência? Poderemos ainda falar de atividade crítica? A reflexão e a consciência crítica terão decaído para abrir espaço a uma atitude, uma postura crítica: por meio dela, o indivíduo não cessa de esquadrinhar, de avaliar, de excluir, de estigmatizar, mas não se compromete, "ela não participa de uma explicação: ela condena” (Gauchet, 2003, p. 349).

Será necessário recordar aqui que aprender é ser capaz de aprender o que ainda não se sabe, o que talvez saberemos depois de tê-lo aprendido, o que também talvez jamais conseguiremos aprender, conhecer e também compreender? É necessário ainda assinalar que aprender supõe a capacidade de comprometer-se e de pensar, de projetar-se no futuro, o que exige e estimula a humildade, a dúvida, o lugar, o risco de erro, o que implica a existência de uma relação no limite, a consciência de limites individuais: atitudes e práticas contrárias às certezas, ao caráter muitas vezes arrogante e peremptório implicado e estimulado pelos saberes

19. A respeito da conivência, o clima, a atmosfera social e política na ascensão do nazismo, ver S. Haffner (2002)

20. Ver Arendt (2005; 1972a; 1972b) e também Voegelin (2003). 
profissionalizados e experientes que se submetem às formas de racionalização e de divisão do trabalho numa economia de mercado ${ }^{21}$.

Sobre as origens e os efeitos desses saberes experientes é que se debruçou lindsay Waters (2004). Ele observa uma crise geral no exercício do juízo, que atribui à pressão a que o mercado submete o trabalho de pensamento: estimulando, privilegiando o automático, o repetitivo, o mercado desenvolve um saber instável, efêmero, não cumulativo ${ }^{22}$. "O universitário típico ressente-se cada vez mais intensamente do fato de que trabalha para produzir", observa ele. "Os chefes de empresa subtraíram todo poder aos cientistas e desenvolveram uma cultura da avaliação que visa a um crescente controle administrativo da vida institucional e profissional”, assinalando com muita justeza que a sociedade está "doente de gestão" (Lawrence apud Waters, 2004, p. 20) ${ }^{23}$.

Waters (2004) percebe "um elo de causa e efeito entre a exigência corporativa de produtividade e o fato de que toda publicação está reduzida à idéia de número" (p. 6) ${ }^{24}$. Ele vê a origem disso em um aumento aparentemente ilimitado do controle administrativo, da gestão, assinala que o mercado gera formas de pressão que aumentam a produtividade e constata que "os problemas de avaliação invadiram hoje em dia as instituições norte-americanas” (p. 7).

0 pensamento individual, original, parece ter declinado diante da corporação, do grupo, do coletivo: submetida à pressão, que se tornou anônima, esse pensamento fundamenta-se e se vê agora legitimado pelo número, a quantidade, e tende, a partir daí, a se tornar cada vez mais homogêneo e conformista.

Waters (2004) debruça-se então sobre a natureza do saber universitário que "supõe a leitura, a apropriação, a transmissão” e aí parece hesitar e, a seguir, explica-se sobre essa hesitação, assinalando o papel decisivo do tempo, da duração, do prazo e da pausa para poder pensar no conhecimento, contrariamente à instantaneidade da informação: "pois pode levar dezenas de anos para que um universitário leia aquela tese em latim da universidade de Berlim, escrita por um certo James Henry Breast, que permite a descoberta do mundo esquecido de Akenaton. 0 papel do saber aprecia-se em termos de profundidade, de duração, não em termos de extensão, de superfície” (p. 19).

0 espírito de empresa, impulsionado atualmente por um movimento incessante, uma atividade desenfreada submetida à urgência, desprovida de reflexão, uma produtividade cega e descomprometida, tenderia a partir de então a ser extirpada das idéias, das mediações, da imaginação: Waters (2004) dedica-se então ao papel da técnica nas sociedades contemporâneas, observando que atualmente "o que conta é o produto" (p. 36) $)^{25}$. Ele constata que "o aumento das exigências em matéria de produtividade é acompanhado de uma interdição aparente em matéria de inovação intelectual” (p. 53), o que ele explica pelo sistema neoliberal que visa a suprimir tudo quanto não seja imediatamente útil ou rentável aos olhos da sociedade.

Em 1941, Fromm dedicara um estudo ao medo da liberdade: agora, Waters (2004) assi-

21. Na conclusão de sua aula inaugural em 2004 , no Collège de France, intitulada Tradition et progrès, la mission de l'université, Théodore Berchem (2004) assinalava "que certas coisas que podem parecer inúteis nas universidades, são de grande utilidade para a sociedade. Recuso-me a querer ou a dever tudo justificar em nome da pertinência social". Berchem recordava finalmente que "a essência mesma das sociedades livres consiste em deixar ao indivíduo uma esfera de atividade autônoma da qual ele não tenha justamente de prestar contas à sociedade. Ao contribuir para a formação do indivíduo, as universidades são, enfim, lugares de liberdade, dessa liberdade institucional e individual que suscita um sentido aumentado de responsabilidade" (p. 59).

22. Lindsay Waters (2004) é o responsável pelas humanidades na Editora Universitária de Harvard. Sobre as origens longínquas dessas questões, ver Weber $(1964 ; 1971)$.

23. Uma análise de conjunto dos efeitos da gestão nas sociedades contemporâneas, particularmente na França, encontra-se em Gaulejac (2004).

24. "Cada vez menos as escolas tolerarão essa espécie de independência relativamente às normas de publicações cada vez mais rígidas. É assim como se as escolas dissessem implicitamente que para ter tenure, você deve provar que não é um espírito independente ao submeter-se às regras e aos fins de uma produtividade intensa" (Waters, 2004, p. 82).

25. Adorno e Horkheimer (1974) dedicaram-se, em estudos pioneiros, a alguns desses aspectos da extensão da técnica em produção industrial de bens culturais. Mais recentemente, Castoriadis (1997) assinalou a existência de uma vasta corrente social e histórica sem autor, sem objetivo, sem projeto. 
nala a urgência de "nos livrarmos do medo de julgar que invadiu a sociedade” (p. 53).

Ele acrescenta, com isso ilustrando a crise da consciência contemporânea e o crescimento do saber não cumulativo, que termos como

consciência, experiência e verdade tornaramse fonte de perplexidades sem fim para a maior parte dos humanistas no correr dos últimos trinta anos. (Waters, 2004, p. 61) ${ }^{26}$

Waters (2004) constata que "a idéia dominante da universidade de hoje em dia é evitar as idéias" (p. 70), levando então a meditar sobre as relações entre, por um lado, computar, medir, avaliar, quantificar e, por outro, ler, pensar, refletir. Em conseqüência, ele nos leva

a ousar propor questões fundamentais, a indagar em primeiro lugar porque alguém quer falar, escrever ou publicar, [...] a se interrogar sobre o fim do saber. (p. 6) ${ }^{27}$

Waters (2004) conclui sua proposição assinalando que o pensamento exige a liberdade, que a exigência de produtividade é contrária a ela na medida em que atinge uma forma de alienação que põe em questão a possibilidade mesma do pensamento: discernindo no termo "autoridade" dois elementos de profundidade diferente: o julgamento, a posição, o comprometimento do autor, e a parte de autoritarismo da componente mecânica, irreversível, acabada do que está impresso, do que é publicado.

Há no pensamento uma parte de liberdade de pensar e de exprimir-se que resiste à sua passagem para a forma material [...], há um conflito que as pessoas profundamente inteligentes sempre experimentarão entre o autoritarismo da obra escrita e a autoridade que se busca ao tomar a palavra e ao publicar. (p. 83-85)

As origens, as condições da crise da consciência contemporânea, a recorrência, a persistência dessa crise, hoje especialmente aguda devido a mudanças, a evoluções profundas, à acumulação de certo número de elementos, não são, no entanto, totalmente inéditas: elas não poderiam assim, paradoxalmente, privar de toda esperança quanto aos "fins da universidade".

Em Voegelin (2003) e Waters (2004), encontramos exposições das quais certos aspectos haviam sido abordados por Weber (1959). Em 1919, em Le savant et le politique, assinalando o surgimento da burocracia, este havia assim previsto sua importância futura:

em inúmeras esferas da ciência, os desenvolvimentos recentes do sistema universitário alemão orientam-se na direção do sistema norte-americano, acrescentando ainda que não é mais possível geri-los sem a ajuda de recursos consideráveis. (p. 56)

Weber (1959) pressentira evoluções cruciais na universidade alemã e, mais além, nos sistemas universitários futuros, relativos à figura do professor e ao papel crescente das massas. Discernira assim dois modelos de comportamentos e de pensamento, irredutíveis e, no entanto, rapidamente confundidos: o do chefe e o do professor da universidade tradicional alemã. Weber revelava assim a existência de um

26. Waters (2004) assinala que os trabalhos de dois autores representativos dessas posições, Fish e Rorty, ilustraram e contribuíram para essa crise da consciência contemporânea, ao descartar, talvez mesmo negar, a questão do indivíduo. A alienação que, na concepção da universidade de Humboldt, tinha a ver com o encerramento na esfera privada, com o descarte da consciência crítica, tenderia a partir de agora à pressão contínua dos fluxos sensoriais contínuos, acarretando a impossibilidade de pensar, de refletir. Sobre essas questões, ver Bauman (2002) e também Gitlin (2002).

27. Waters (2004) se volta para os trabalhos de Fish, sem Ihe atribuir uma importância que ele não poderia ter, vendo nesse autor um tipo ideal, uma figura emblemática das formas de relativismo profundo e de niilismo insidioso que hoje envolvem as ciências humanas e, mais além, as sociedades democráticas contemporâneas. "Penso que o que Fish realmente buscou reduzir não foi somente a teoria, mas as jovens gerações universitárias que nela se aventuram e que esperam que a teoria ou alguma outra coisa [...] possa fazer a menor diferença. Ele não se opõe tanto à teoria, mas à conseqüencialidade, à causalidade mesma, à idéia de que o que quer que seja possa fazer uma diferença em nossas vidas" (p.69). 
"abismo" nos tipos de personalidade, nos traços de caráter, nas condutas visíveis, nas condutas mais intimas,

exterior e interiormente, entre o chefe dessa espécie de grande empresa universitária capitalista e o costumeiro professor titular ao velho estilo. (p. 57) ${ }^{28}$

Aí, nesse processo, é que o talento do orador - o carisma - se confunde com a profundidade do pensamento do erudito, por vezes concentrado sobre si mesmo e silencioso, pensamento esse imponderável e indominável em grande parte; é aí ainda que se podia discernir o papel grandioso do número, a exigência da utilidade para o maior número: ela se desenvolvia contra o valor reconhecido à singularidade, à originalidade do indivíduo. Pode-se então compreender, concluía Weber (1959), que "o número dos ouvintes" tenha se tornado "um critério numérico tangivel do valor, uma vez que a qualidade do erudito é da esfera do imponderável”: a massa se erguia a partir de então contra a aristocracia intelectual, fazendo pensar na precaução de Weber:

é preciso pôr a democracia no lugar que lhe convém. De fato, a educação científica tal como devemos oferecê-la por tradição nas universidades alemãs é uma questão de aristocracia espiritual. (p. 60-61)

Isso se dá porque tudo está quase sempre subordinado à obsessão da sala cheia, observa ainda Weber (1959). Voegelin, em tom polêmico, cruzando elementos da análise de Weber e recordando também a análise que, em 1933, Reich dedicara à psicologia de massa do fascismo, pôs em evidência essas evoluções da universidade: mostra assim que essa aristocracia sob o Terceiro Reich foi sociologicamente maltratada:

no interior da universidade, os assassinatos e as expulsões atingiram sobretudo a elite espiritual e intelectual, de cuja qualidade dependem o nível cultural do conjunto do institucional e a conser- vação das normas. [...]. Após a ruptura de continuidade sobrevinda no seio da elite, o meio dos universitários de segunda categoria que, protegido pela sombra protetora de sua discrição e de sua adaptabilidade [...] comanda de maneira desmedida a estrutura da universidade [...] desde que se alteraram as proporções entre as camadas universitárias superiores e o meio de segunda categoria da universidade, pode-se observar um provincialismo agressivo. A destruição da substância pelo nazismo foi de tal amplitude que ainda não se pode observar todas as suas conseqüências e que o pior talvez ainda esteja por vir. Eis por que é muito mais difícil hoje em dia do que na década de 1920 resolver os problemas da universidade alemã. (p. 335)

Percebendo o permanente estado inacabado e o caráter provisório do conhecimento, Weber (1959) propusera que a crise da consciência é intrínseca ao pensamento, ao conhecimento; "não é tão evidente que um fenômeno que obedece a essa lei do progresso possua em si mesmo sentido e razão" (p. 68), escreveu ele. "Por que então nos entregamos a uma ocupação que na realidade jamais tem um fim e não pode tê-lo [...] qual é a posição pessoal do homem de ciência diante de sua vocação? Que obra significativa espera ele então realizar graças a suas descobertas invariavelmente destinadas a envelhecer, sempre se deixando arrastar por aquele empreendimento dividido em especialidades e que se perdem no infinito?" Ele lembrava que

o progresso científico é um fragmento, é verdade que o mais importante, desse processo de intelectualização a que estamos sujeitos há milênios e relativamente ao qual certas pessoas adotam nos dias de hoje uma posição estranhamente negativa. (p. 68-69) ${ }^{29}$

28. Sobre essa oposição modelo de chefe/modelo de professor, ver Haroche (2005)

29. Devemos lembrar, aqui, que Weber era crítico relativamente à noção de progresso inscrito na racionalidade capitalista surgida no século XVIII. 
Estará esse processo de intelectualização obstruído nas sociedades contemporâneas, sendo então colocada de novo agudamente a questão do sentido, do insignificante? Assume ele hoje em dia formas inéditas que levam a meditar e a considerar o papel do movimento, da sensação e do corpo na capacidade de pensar e no exercício de uma consciência moral?

Fortalecido, aumentado pela falta de tempo, pelo descompromisso, pela aceleração e pelos fluxos sensoriais e informacionais contínuos, pela fluidez das sociedades contemporâneas, o exercício da consciência é reduzido pelas exigências contemporâneas da produtividade intensa, intensificando a descontinuidade, a fragmentação, e aí a superficialidade, a ausência de discernimento.

A leitura de Weber leva a aprofundar as nuances impalpáveis e inatingíveis do comportamento íntimo, da consciência que, nascidas hoje da desatenção, da lassitude, da fadiga, da anomia, ou ainda do desencanto, da confusão, do mal estar, abriga e oculta no mais profundo da subjetividade atitudes de conivência que podem, pouco a pouco, insidiosamente levar a um niilismo difuso e a uma violência radical.

\section{Referências bibliográficas}

ADORNO, T. W. Jargon de l'authenticité de l'idéologie allemande (1964). Paris: Payot, 1989.

ADORNO, T. W.; HORKHEIMER, M. La dialectique de la raison (1944). Paris: Gallimard, 1974.

ANZIEU, D. Le moi peau (1985). Paris: Dunod, 1995.

ARENDT, H. Considérations morales (1971). Paris: Rivage, 1996.

. La crise de l'éducation. In: . La crise de la culture (1954). Paris: Gallimard, 1972a.

La vie de l'esprit (1971). Paris: PUF, 2005.

Qu'est ce que l'autorité? In: La crise de la culture (1954). Paris: Gallimard, 1972b.

Vies politiques. Paris: Gallimard, 1974.

AUBERT, N. L'individu hypermoderne. Paris: Erès, 2004.

BALIBAR, E. Violence: idéalité et cruauté. In: Héritier-Auge, F. De la violence. Paris: Odile Jacob, 1996.

BAUMAN, Z. Liquid modernity. Cambridge: Polity Press, 2000.

Society under siege. Cambridge: Polity Press, 2002.

BENJAMIN, W., L'CEuvre d'art à l'époque de sa reproductibilité technique (1939). CEuvres III, Paris, Gallimard (folio essais), 2000.

BERCHEM, T. Tradition et progrès, la mission de l'université. Paris: Collège de France/Fayard, 2004.

BERGSON, H. La pensée et le mouvant: essais et conférences (1938). Paris: PUF, 2003.

BOBBIO, N. Le sage et la politique: écrits moraux sur la vieillesse et la douceur (1996). Paris: Albin Michel, 2004.

CASTORIADIS, C. La montée de l'insignifiance. Paris: Seuil, 1997.

La rationalité du capitalisme. In: Les carrefours du labyrinthe VI: figures du pensable. Paris: Seuil, 1999.

L'institution imaginaire de la société. Paris: Seuil, 1975. 
DUMONT, L. L'idéologie allemande. Paris: Gallimard, 1991.

ELLUL, J. Propagandes. Paris: Economica, 1990.

GAUCHET, M. Démocratie, éducation, philosophie. In: BLAIS, M.C.; GAUCHET, M.; OTTAVI, D. (Orgs.). Pour une philosophie politique de l'éducation. Paris: Bayard, 2002.

La condition historique. Paris: Stock, 2003

GAULEJAC, V. de. La société malade de la gestion: idéologie gestionnaire, pouvoir managérial et harcélement social. Paris: Seuil, 2004.

GITLIN, T. Media unlimited (How the torrent of images and sounds overwhelms our lives). Nova York: Henry Holt, 2002.

HAFFNER, S. Histoire d'un allemand: souvenirs 1914-1933. Arles: Actes Sud, 2002.

HAROCHE, C. A personalidade não-totalitária. In: DUARTE, A.; LOPREATO, C.; MAGALHÃES, M. (Orgs.). A banalização da violência: a atualidade do pensamento de Hannah Arendt. Rio de Janeiro: Relume Dumara, 2004a.

Des formes et des manières en démocratie. Raisons politiques. Paris: Presses de Science Pol, n. 1, fev/avril, 2001.

Descontinuidade e intangibilidade da personalidade: a relação com o tempo no individualismo contemporâneo. Art cultura, Revista do Instituto de História da Universidade Federal de Uberlândia, n. 19, jul./dez. 2004b.

Le pouvoir absolutiste face aux manières conviviales des cercles au XVIlème siècle (1954). Politix, n. 26, 1994.

Maneiras de ser, maneiras de sentir do indivíduo hipermoderno. Agora: Estudos em Teoria Psicanalítica, Rio de Janeiro, V. VII, p. 221-234, dez. 2004c. 2004d.

Manières de regarder dans les sociétés contemporaines. Communications: le sens du regard, n. 75, p. 147-169,

Modos de subjetivação e tipos de aspirações nos movimentos de juventude, 1914-1933. In: Guglielmi, G. J.; Haroche, C.

(Orgs.). Esprit de corps, démocratie et espace public. Paris: PUF, 2005.

HAZARD, P. La crise de la conscience européenne. Paris: Fayard, 1935.

HUSSERL, E. La crise des sciences européennes et la phénoménologie transcendentale (1936). Paris: Gallimard, 1972.

ILLICH, I. La perte des sens. Paris: Fayard, 2004.

JANET, P. L'automatisme psychologique (1889). Paris: Société Pierre Janet et le Laboratoire de psychologie pathologique de la Sorbonne avec le concours du CNRS, 1989.

KAUFFMANN, J. C. Tout dire de soi, tout montrer. Le Débat, n. 125, 2003.

LOCKE, J. Essai sur l'entendement humain. Livres I e II (1690). Paris: Vrin, 2001.

MCLUHAN, M. Pour comprendre les media: les prolongements technologiques de l'homme. Paris: Seuil, 1968.

MERLEAU-PONTY, M. Phénoménologie de la perception (1945). Paris: Gallimard, 2001.

SENNETT, R. Le travail sans qualités (1998). Paris: Albin Michel, 2000.

TURCKLE, S. Life on the screen: identity in the age of internet. Nova York: Touchstone, 1995.

VOEGELIN, E. Hitler et les allemands (1964). Paris: Seuil, 2003.

WATERS, L. Enemies of promise. Chicago: University of Chicago Press, 2004. 
WEBER, M. Economie et société: les catégories de la sociologie. Tome 1. Paris: Plon, 1971.

Le savant et le politique. Paris: Plon, 1959.

L'éthique du protestantisme et l'esprit du capitalisme (1947). Paris: Plon, 1964.

Recebido em: 09.06.05

Aprovado em: 07.11 .05

Claudine Haroche é diretora de pesquisas do CNRS junto ao Centre d'Études Transdisciplinaires - Sociologie,Anthropologie, Histoire. Atualmente tem como temas de pesquisa as condutas corporais e o funcionamento psíquico, a construção do indivíduo moderno, o caráter e a personalidade na contemporaneidade. Publicou no Brasil o livro Da palavra ao gesto (Papirus, 1998). 